Review

\title{
Surface Sensitive Techniques for Advanced Characterization of Luminescent Materials
}

\author{
Hendrik C. Swart \\ Department of Physics, University of the Free State, P.O. Box 339, Bloemfontein ZA93002, South Africa; \\ swarthc@ufs.ac.za; Tel.: +27-514012926
}

Received: 25 May 2017; Accepted: 1 August 2017; Published: 4 August 2017

\begin{abstract}
The important role of surface sensitive characterization techniques such as Auger electron spectroscopy (AES), X-ray photo electron spectroscopy (XPS), time of flight scanning ion mass spectrometry (TOF-SIMS) and High resolution transmission electron microscopy (HRTEM) for the characterization of different phosphor materials is discussed in this short review by giving selective examples from previous obtained results. AES is used to monitor surface reactions during electron bombardment and also to determine the elemental composition of the surfaces of the materials, while XPS and TOF-SIMS are used for determining the surface chemical composition and valence state of the dopants. The role of XPS to determine the presence of defects in the phosphor matrix is also stated with the different examples. The role of HRTEM in combination with Energy dispersive spectroscopy (EDS) for nanoparticle characterization is also pointed out.
\end{abstract}

Keywords: AES; XPS; TOF-SIMS; HRTEM; CL degradation; valence state; phosphors

\section{Introduction}

With the development of flat panel displays (FPDs) and light emitting diodes (LEDs), phosphor materials became an integral part of our life style. Luminescent compounds and materials also have numerous other uses such as temperature sensors, radiation dosimeters, optical probes, storage phosphor imaging, medical imaging, microscopy techniques, homeland security, detecting tools of biological structures and can possibly be used as efficient improvement of solar cells [1-3]. The emission properties, whether of a fast decay rate fluorescent material or a slow decay rate phosphorescent material, depend on the chemical composition of the host and the physical structure thereof as well as the dopants and defect concentration of the luminescent material [1]. Material synthesis conditions, binder characteristics, absorbing dyes usage, etc. also play important roles in the luminescent properties. The host, valence state and crystal field are the most important properties of phosphors to be reckoned with in the design of new phosphor materials [4-8]. The crystal field due to the local host environment in combination with the dopant ion with the correct valence/oxidation state can be used to obtain emissions from the Ultra violet (UV) to the Infra-red (IR) wavelength ranges.

It remains important to be able to experimentally verify the oxidation state of the rare earth (RE) ions [9]. As an example, $\mathrm{Ce}^{3+}$ ions are good activators as well as useful sensitizers [10]. On the other hand, the possibility of $\mathrm{Ce}$ ions being found in the tetravalent $\mathrm{Ce}^{4+}$ oxidation state, which is non-luminescent, creates some difficulties in using these ions as luminescent centers in phosphors. Similar to Ce, the lanthanide Eu can also occur in two different valence states $\left(\mathrm{Eu}^{2+} / \mathrm{Eu}^{3+}\right)$, and, although both of these are luminescent, their emission properties are very different. Eu ${ }^{2+}$ has emission from an allowed d-f transition, which is host dependent, whereas $\mathrm{Eu}^{3+}$ has emission from forbidden $\mathrm{f}-\mathrm{f}$ transitions at wavelengths that do not vary with the host material.

Several analytical methods have been reported for low-level monitoring of RE ions in various sample matrices [11]. These methods include inductively coupled plasma mass spectroscopy 
(ICP-MS) [12], inductively coupled plasma atomic emission spectroscopy (ICP-AES) [13], isotope dilution mass spectrometry [14], resonance light scattering (RLS) [15], voltammetry [16], capillary electrophoresis [17], X-ray fluorescence (XRF) [18], fluorimetry [19], ion-microprobe [20] and other methodologies [21].

The stability of these phosphors under electron or photon irradiation is important for the FPD and LED market. The effects of bombarding with electrons vary from the development of charge, to quenching of the radiative decay of the activator excited states, to the dissociation of the gaseous or surface absorbed species causing the growth of oxide or carbon films on the surface (i.e., development of a surface "dead layer") [22], creating defects in the surface and interface layers. Abrams and Holloway [23] discussed the development of the "dead layers", defined to be a surface layer with no or weak luminescence. The molecular dissociation, surface chemical reactions and desorption of neutral and/or ionic atoms and/or molecules by electron or photon primary beams have been known since the 1950s to be important in surface and vacuum physics [24]. For example, electron-stimulated-desorption (ESD) was first observed because of its effects on the accuracy of vacuum pressure measurements using a hot filament ionization of a high vacuum gauge. ESD and many similar phenomena resulting from electron and photon interactions with solid surfaces are described in the book by Redhead et al. [25]. Duvenhage et al. [26] showed a 60\% decrease in luminescence intensity upon UV light exposure of a mer-tris-8-hydroxy-quinolinato-indium (III) complex used in organic light emitting diodes (OLEDs). This was an indication that oxygen in moisture in the air caused some of the phenoxide rings in the complex to decompose and destroy the luminescent centers in the process. Surface characterization techniques play a vital role in the complete understanding of the luminescent properties and oxidation states of phosphor materials [8]. Auger electron spectroscopy (AES), X-ray photo electron spectroscopy (XPS), time of flight scanning ion mass spectrometry (TOF-SIMS) and High resolution transmission electron microscope (HRTEM) are used to characterize different phosphor materials. The important role of these techniques is illustrated in this paper by using example studies from previous published work.

\section{Experimental Setup}

Phosphor materials are normally prepared with different synthesized methods such as chemical bath deposition (CBD) [27], sol-gel [5,7], combustion [4], sol-gel combustion [28], hydro thermal [29], solid-state reaction [30,31], etc. Surface characterization and morphology of these phosphors are important and are carried out with AES, XPS, TOF-SIMS and HRTEM. The optical characterization is carried out with photoluminescence (PL), cathodoluminescence (CL), UV-Vis, Fourier transformed infra-red (FTIR) and Raman spectroscopy. The stability and degradation of these phosphors are important properties that are studied on a regular basis, especially for applications in display technologies.

\section{1. $C L$ and $A E S$}

Figure 1 shows the experimental setup for an in-house CL intensity degradation system. The same electron beam that is used to excite the Auger electrons of the phosphor surface is simultaneously been used to excite the phosphor material. Basically, the changes in intensity of the different CL peaks and Auger peak to peak heights (APPH) are monitored and compared with each other. The system consists of an AES vacuum system coupled with a CL spectrometer (Ocean Optics, Inc., Dunedin, FL, USA). The PHI (model 549) Auger spectrometer (Physical Electronics, INC. (PHI), Chanhassen, MN, USA) and Ocean Optics (S2000) spectrometer (Ocean Optics, Inc., Dunedin, FL, USA) are simultaneously used to collect the Auger and CL data, respectively. The light output is collected via a fiber optic connected to the CL spectrometer. The primary AES electron beam current can be adjusted and is typically between 6 and $12 \mu \mathrm{A}$. The beam size is varied from 100 to $300 \mu \mathrm{m}$ depending on the focus of the beam and the beam voltage and beam current. Beam densities vary between 2.5 and $88 \mathrm{~mA} / \mathrm{cm}^{2}$. The Auger and CL data are collected in a vacuum chamber with an initial base pressure in the low $10^{-9}$ Torr range, where after the chamber maybe backfilled with $\mathrm{O}_{2}, \mathrm{~N}_{2}$ or $\mathrm{CO}_{2}$ up to 
pressures of $10^{-6}$ Torr during the degradation study. Throughout the experiment, the Auger and CL data are recorded using the same adjustable primary electron beam of 1 to $5 \mathrm{keV}$. The decrease of the CL intensities and the surface chemical changes during prolonged electron bombardment of the phosphors is monitored continuously for periods up to $24 \mathrm{~h}$ at the desired different gas pressures.

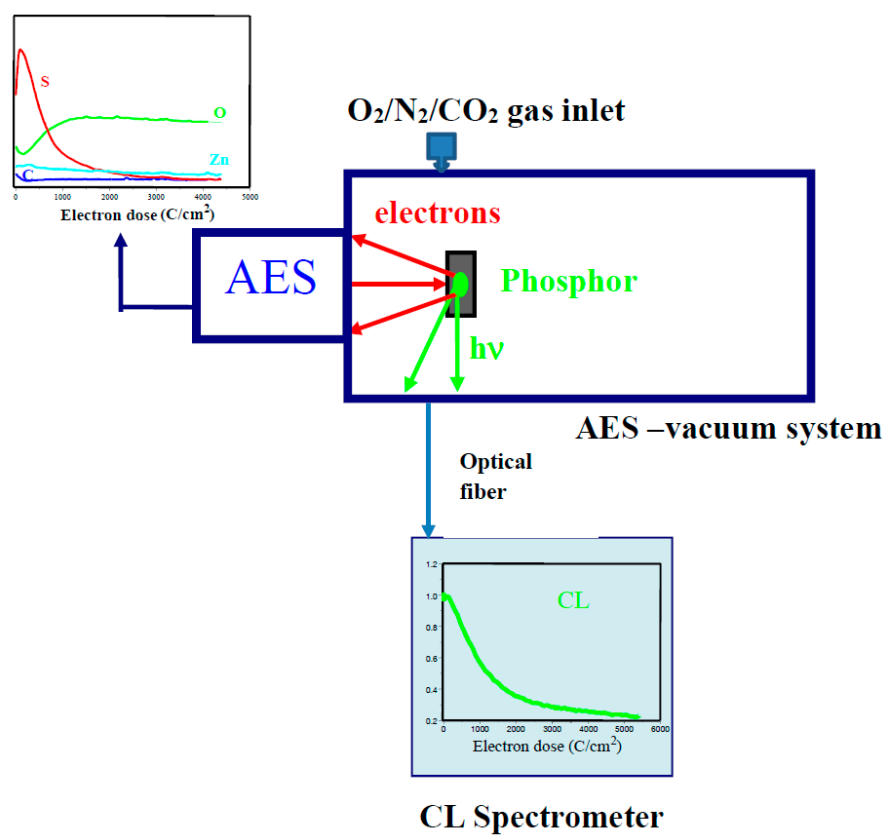

Figure 1. The CL/AES setup for electron degradation measurements.

\subsection{XPS}

The surface chemical changes are then determined with the use of XPS. The XPS data are collected before and after degradation to evaluate the chemical composition and electronic states of the different elements. The data are collected using the PHI 5000 Versa probe-Scanning ESCA microprobe (Physical Electronics, INC. (PHI), Chanhassen, MN, USA). Low energy $\mathrm{Ar}^{+}$ion gun and low energy neutralizer electron gun are used to minimize charging on the surface. Monochromatic $\mathrm{Al}$ $\mathrm{K} \alpha$ radiation $(h v=1486.6 \mathrm{eV})$ is used as the excitation source. A $25 \mathrm{~W}, 15 \mathrm{kV}$ electron beam is used to excite the $\mathrm{X}$-ray beam of $100 \mu \mathrm{m}$ diameter, that is used to analyze the different binding energy peaks (pass energy $11 \mathrm{eV}$, analyzer resolution $\leq 0.5 \mathrm{eV}$ ). Multipak version 8.2 software [32] is used to analyze the chemical elements and their electronic states using Gaussian-Lorentz fits. The valence state and site positions of the dopants are also confirmed with XPS.

\subsection{TOF-SIMS}

Furthermore, TOF-SIMS measurements were performed on a PHI TRIFT V nanoTOF (Physical Electronics, INC. (PHI), Chanhassen, MN, USA) or ION TOF-SIMS (Ion-tof GmbH, Münster, Germany) by using a pulsed $\mathrm{Au}^{+}$or $\mathrm{Bi}^{+}$primary ion beam, to acquire chemical images of the phosphor in both the positive and the negative secondary ion polarities. The analytical field-of-view is typically $200 \mu \mathrm{m} \times 200 \mu \mathrm{m}$ with a 256 pixel $\times 256$ pixel digital raster, and the primary ion dose is maintained well within the static limit for each analysis. Charge compensation is achieved with a dual-beam $\left(\leq 15 \mathrm{eV} \mathrm{e}^{-}\right.$and $\left.\leq 10 \mathrm{eV} \mathrm{Ar}^{+}\right)$charge neutralizer. A raw data stream file is collected to allow full post-acquisition evaluation (i.e., retrospective analysis) of the data. 


\subsection{HRTEM}

HRTEM is performed by using a JEM-2100 electron microscope (JEOL, Tokyo, Japan) at a beam voltage of $200 \mathrm{keV}$. The EDS (Energy Dispersive X-ray Spectrometer, Oxford Instruments plc, Oxfordshire, UK) mapping and chemical composition analysis is performed with an Oxford XMax 80 EDS detector (Oxford Instruments plc, Oxfordshire, UK). The ImageJ software (Laboratory for Optical and Computational Instrumentation, Wisconsin-Madison, WI, USA) is used to determine the size of the nanoparticles (NPs) from the obtained SEM/TEM micrographs. PL is done with a Cary Eclipse (Agilent, Santa Clara, CA, USA) equipped with a $150 \mathrm{~W}$ Xenon lamp and a $325 \mathrm{~nm}$ He-Cd laser. Raman spectra are obtained by using a NXR FT-Raman module microscopy (Thermo Fisher Scientific Inc, Madison, WI, USA) system with a $2.5 \mathrm{~W} \mathrm{Nd}: \mathrm{YVO}_{4}$ laser excitation of a $1064 \mathrm{~nm}$ wavelength and a high-performance liquid nitrogen-cooled germanium detector.

\section{Results and Discussion}

\subsection{Electron Degradation-AES and XPS}

\subsection{1. $\mathrm{ZnS}$}

A typical electron degradation study ends up with: (a) an APPH spectrum as a function of time; and (b) a CL intensity as function of time, as demonstrated for a ZnS phosphor exposed to an electron beam as indicated in Figure 2 [33]. Figure 2a shows the APPHs of the different elements present on the surface during the degradation study, S (152 eV), C (272 eV), O (511 eV) and Zn $(994 \mathrm{eV})$, against electron dose during $2 \mathrm{keV}, 64 \mathrm{~mA} \mathrm{~cm}^{-2}$ electron bombardment at an oxygen pressure of $1 \times 10^{-6}$ Torr. Oosthuizen et al. [33] found that the C APPH immediately decreased exponentially when the surface was exposed to the electron beam. The $C$ on the phosphor surface was present from adventitious atmospheric contamination. Simultaneous to the time when the $\mathrm{C}$ decreased, the $\mathrm{CL}$ intensity stayed more or less constant (Figure 2b), which indicated that the $C$ on the surface acted as a protected layer for the $\mathrm{CL}$ degradation. The $\mathrm{S} A P P H$ at first increased due to the removal of the $\mathrm{C}$ from the surface and then started to decrease exponentially while the $\mathrm{O}$ increased after most of the $\mathrm{C}$ was removed from the surface. With the increase in the $\mathrm{O}$ and decrease in S APPHs the CL also decreased, which showed a direct correlation between the surface reactions and the CL intensity changes. It was found by Oosthuizen et al. [33] that $\mathrm{ZnO}$ has formed on the surface of the $\mathrm{ZnS}$ under prolonged electron bombardment. They also measured the presence of $\mathrm{SO}_{2}$ gas during electron bombardment. Itoh et al. [34], using XPS, reported that $\mathrm{ZnSO}_{4}$ was formed on the surface of the $\mathrm{ZnS}$ phosphor during electron irradiation in a $\mathrm{H}_{2} \mathrm{O}$ ambient. Both $\mathrm{ZnO}\left(-94.43 \mathrm{kcal} / \mathrm{mol} \mathrm{O}_{2}\right)$ and $\mathrm{ZnSO}_{4}(72.09 \mathrm{kcal} / \mathrm{mol}$ $\mathrm{O}_{2}$ ) have a negative heat of formation [33]. The degraded layer grew in thickness with prolonged electron irradiation time. Chen et al. [35] found a linear growth rate (Figure 3a) for the $\mathrm{ZnO}$ layer in a wet oxygen atmosphere and a $\mathrm{ZnSO}_{4}$ formation that decayed exponentially with time and it was postulated that this was due to the diffusion of the charge reactants through the $\mathrm{ZnSO}_{4}$ film to the reaction interfaces, as shown in Figure 3b. During the course of electron irradiation the bombarded areas of the phosphor became darkened in color and degraded in CL efficiency, as pointed out by the Secondary X-ray Imaging in Figure 4a. XPS was used to determine the chemical species in the degraded spot as well as on the undegraded area. A schematic of the degraded spot and growth of the non-luminescent layer with electron bombardment time is shown in Figure $4 \mathrm{~b}$. Holloway and Swart [36,37] came up with a well-known ESSCR (electron stimulated surface chemical reaction) mechanism that was applied to the degradation of several phosphors. According to this model, reactive gas molecules adsorb on the surface of the $\mathrm{ZnS}$ phosphor and are dissociated to reactive atomic species by the electron beam. This results in the formation of a non-luminescent $\mathrm{ZnO} / \mathrm{ZnSO}_{4}$ layer on the surface and volatile $\mathrm{SO}_{2}$ as illustrated in Figure 5. 

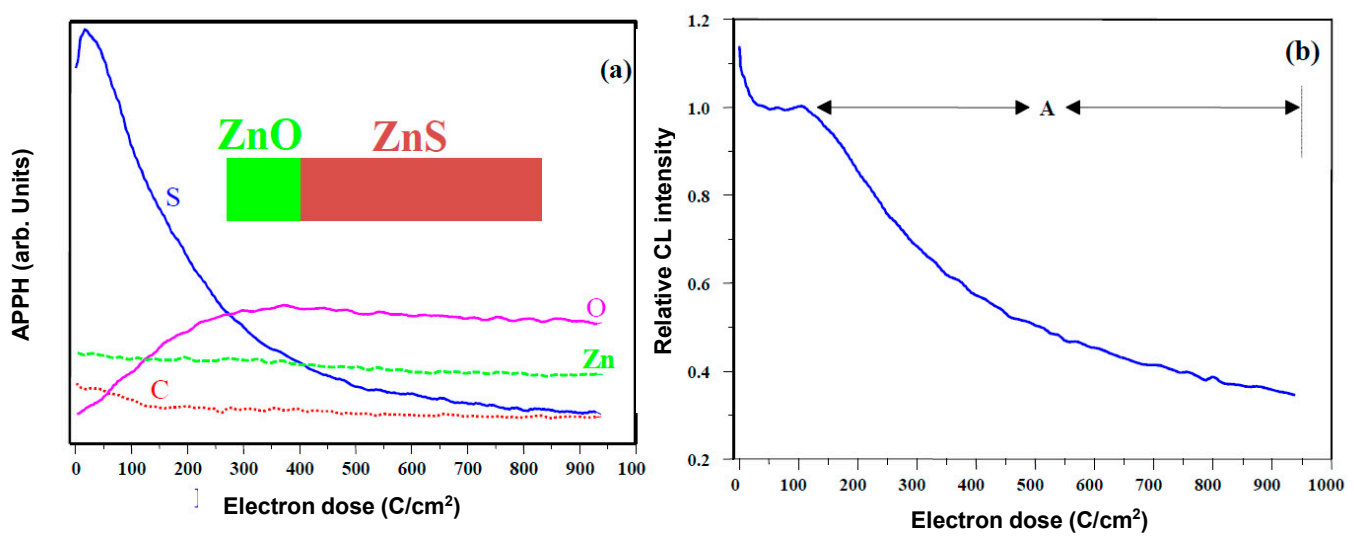

Figure 2. The (a) APPHs; and (b) CL intensity of $\mathrm{ZnO}$ during prolonged electron bombardment as function of electron dose [11].
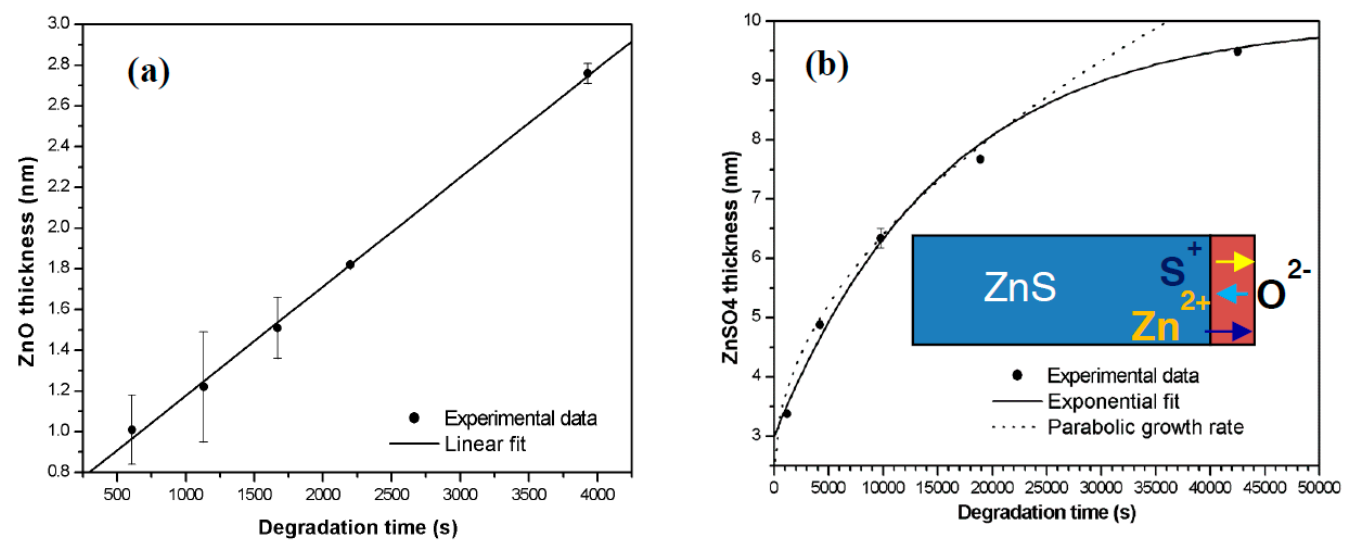

Figure 3. (a) $\mathrm{ZnSO}_{4}$; and (b) $\mathrm{ZnO}$ layer growth in dry and a wet oxygen atmosphere as function of degradation time with an illustration of the diffusion of the charge reactants during the $\mathrm{ZnSO}_{4}$ formation as an inset [35].

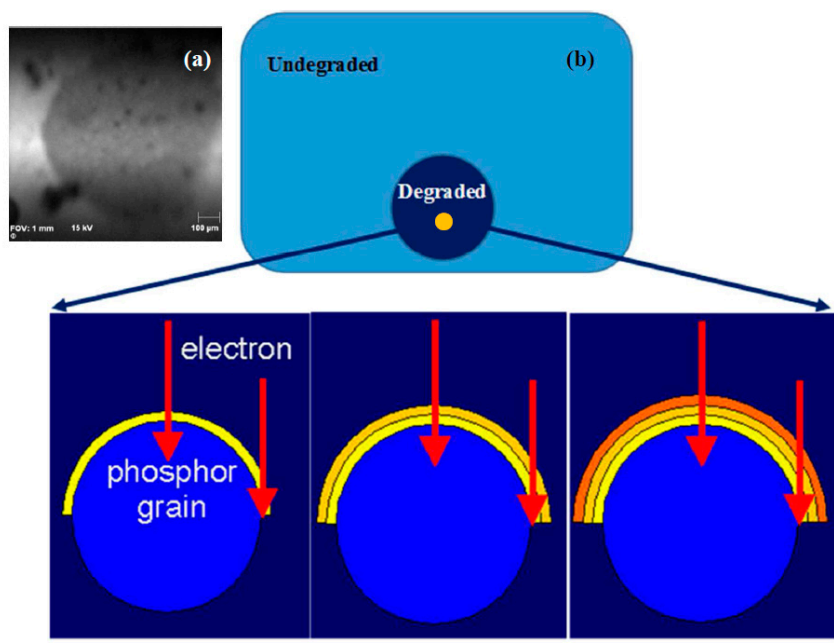

\section{time}

Figure 4. (a) A schematic of the degraded spot with an enlargement of one of the particles showing the growth of the degraded thin film with prolonged electron bombardment time; and (b) secondary $X$-ray Imaging (SXI) of a $24 \mathrm{H}$ degraded spot of $\mathrm{Y}_{2} \mathrm{SiO}_{5}$ :Ce. 


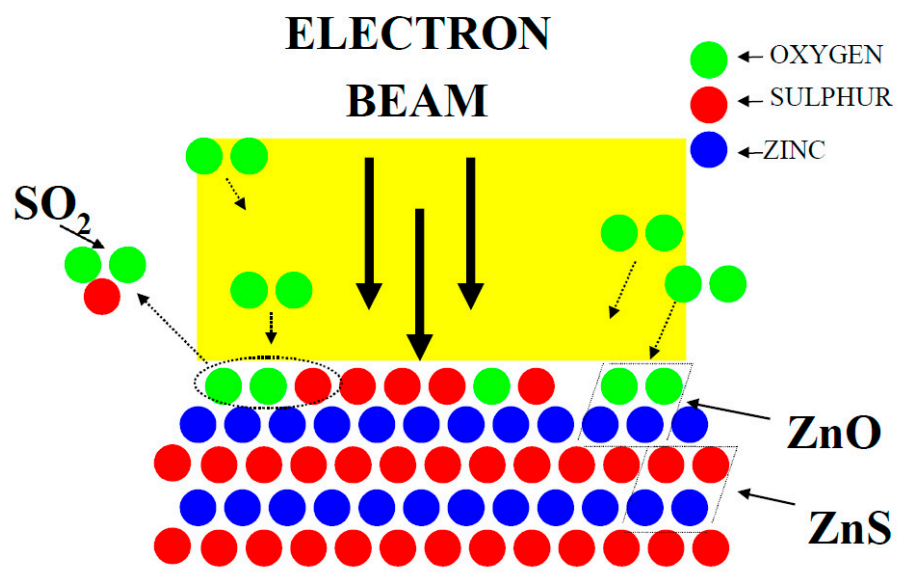

Figure 5. Schematic illustration of the ESSCR mechanism.

\subsection{2. $\mathrm{Sr}_{5}\left(\mathrm{PO}_{4}\right)_{3} \mathrm{~F}: \mathrm{Eu}$}

As mentioned, other phosphors showed that the ESSCR mechanism could also be used to explain the degradation thereof. Figure 6 illustrates the comparative PL emissions of undegraded and degraded CL emission spectra of $\mathrm{Sr}_{5}\left(\mathrm{PO}_{4}\right)_{3} \mathrm{~F}: \mathrm{Eu}$ at an oxygen pressure of $1 \times 10^{-6}$ Torr [5]. This is a good example where the $\mathrm{CL}$ emission spectrum consists of both $\mathrm{Eu}^{2+}$ as well as $\mathrm{Eu}^{3+}$ emission. The $\mathrm{Eu}^{2+}$ wavelength position is matrix sensitive, while the $\mathrm{Eu}^{3+}$ emission wavelength position is not affected by a change in the matrix. The $\mathrm{Eu}^{2+} \mathrm{CL}$ emission appeared as a broad band with the maxima centred at $430 \mathrm{~nm}$ due to the $4 \mathrm{f}^{6} 5 \mathrm{~d} \rightarrow 4 \mathrm{f}^{7}$ transition and is more prominent compared to the PL emission. The prominent $\mathrm{Eu}^{2+} \mathrm{CL}$ emission was obtained due to the blue emitting $4 \mathrm{f}^{6} 5 \mathrm{~d}$ level that can be populated using high energy excitation such as cathode rays [38]. The $4 f^{6} 5 d \rightarrow 4 f^{7}$ transitions of $\mathrm{Eu}^{2+}$ require assistance from low frequency phonons of the host matrix. In addition, the energy position of the $4 \mathrm{f}^{6} 5 \mathrm{~d}$ must be blue shifted to allow population of the ${ }^{5} \mathrm{D}_{0}$ state by a direct non-radiative relaxation process. The Eu ${ }^{3+}$ emission at $593,616 \mathrm{~nm}$ due to ${ }^{5} \mathrm{D}_{0} \rightarrow{ }^{7} \mathrm{~F}_{1},{ }^{7} \mathrm{~F}_{2}$ transition and $578 \mathrm{~nm}$ due to ${ }^{5} \mathrm{D}_{0} \rightarrow{ }^{7} \mathrm{~F}_{0}$ appeared [39] as a mirror image of the PL spectrum. After degradation, it appears that the blue emission of the $\mathrm{Eu}^{2+}$ ions was centered at $420 \mathrm{~nm}$ and remained prominent and shifted $\approx 10 \mathrm{~nm}$ compared to the undegraded sample. The $\mathrm{CL}$ intensity of the red emission due to the $\mathrm{Eu}^{3+}$ decreased drastically with an increasing in electron dose of 0 to $450 \mathrm{C} / \mathrm{cm}^{2}$. According to the ESSCR model, the $\mathrm{Sr}-\mathrm{O}, \mathrm{Sr}-\mathrm{F}$ and $\mathrm{P}-\mathrm{O}$ bonds are likely to be broken into free oxygen, fluoride, strontium and phosphorous when irradiated with a beam of electron. This will be followed by a chemical reaction resulting in new chemical compounds forming on the surface. In most cases, the new oxide layers are non-luminescent, and therefore will reduce the $\mathrm{CL}$ intensity. Simultaneous to the $\mathrm{O}_{2}$ desorption during $\mathrm{CL}$ degradation, it is most likely that $\mathrm{P}$ (metallic), $\mathrm{SrO}$ [40] and $\mathrm{P}_{2} \mathrm{O}_{5}$ [41] mixed layers were formed on the surface according to the ESSCR mechanism. The $\mathrm{Eu}^{3+}$ emission mostly arises from the site occupancy of the $\mathrm{Sr}_{2}$ metal sites which are present on the outer surface of the crystal. This caused the decrease in the $\mathrm{Eu}^{3+} \mathrm{CL}$ intensity during prolonged electron exposure. The ${ }^{5} \mathrm{D}_{0}{ }^{7} \mathrm{~F}_{0}(578 \mathrm{~nm})$ and ${ }^{5} \mathrm{D}_{0}{ }^{7} \mathrm{~F}_{2}(616 \mathrm{~nm}) \mathrm{Eu}^{3+}$ emission behavior depends on the site symmetry behavior. The slight shift of the 653 and $705 \mathrm{~nm} \mathrm{Eu}^{3+} \mathrm{CL}$ emissions arise due to crystal ligand field splitting and asymmetrical environment of the crystal [39]. Simultaneously, the $\mathrm{Eu}^{2+}$ emission arises from the Eu ion which is present near to the defect centers, which remains protected. Thus, $\mathrm{Eu}^{2+} \mathrm{CL}$ intensity remains intact during prolonged electron beam exposure. The shift in the peak position, however, indicates a change in the crystal field due to a change in the host lattice. 


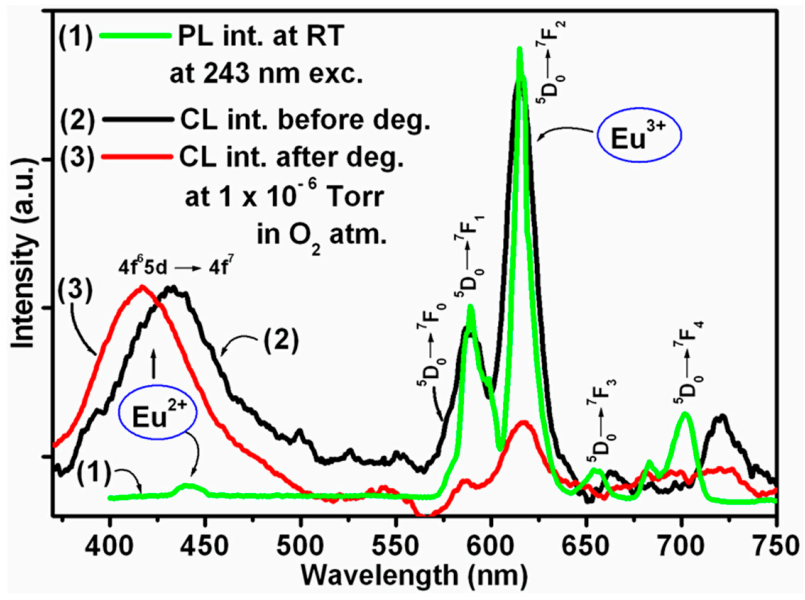

Figure 6. The comparative PL and CL output of the $\mathrm{Sr}_{5}\left(\mathrm{PO}_{4}\right)_{3} \mathrm{~F}: \mathrm{Eu}$ as function of Coulomb dose at $1 \times 10^{-6}$ Torr $\mathrm{O}_{2}$ atmosphere under electron beam excitation with the primary beam voltage and beam current of $2 \mathrm{keV}$ and $10 \mu \mathrm{A}$, respectively [5].

\subsection{3. $\mathrm{Y}_{2} \mathrm{SiO}_{5}: \mathrm{Ce}^{3+}$}

During the degradation studies of $\mathrm{Y}_{2} \mathrm{SiO}_{5}: \mathrm{Ce}^{3+}$, an increase in the CL intensity at a wavelength of $650 \mathrm{~nm}$ was measured (Figure 7a) [42]. The XPS (Figure 8a) and CL (Figure 7a) indicated that the electron stimulated reaction led to the formation of a luminescent silicon dioxide $\left(\mathrm{SiO}_{2}\right)$ layer on the surface of the $\mathrm{Y}_{2} \mathrm{SiO}_{5}$ :Ce phosphor powder. The first spectrum (Figure 7a) is characteristic of the doublet character of the blue light emission from $\mathrm{Ce}^{3+}$, due to the $4 \mathrm{f}$ ground state splitting $[43,44]$. Figure 8a shows the fitted results from an XPS spectrum for the Si $2 p$ peak in the $\mathrm{Y}_{2} \mathrm{SiO}_{5}$ state and after $24 \mathrm{~h}$ in the $\mathrm{SiO}_{2}$ state. The $\mathrm{Si} 2 \mathrm{p}$ peak shifted and changed shape from the yttrium silicate $\left(\mathrm{Y}_{2} \mathrm{SiO}_{5}\right)$ chemical state with binding energy $101.3 \mathrm{eV}$ to the silica $\left(\mathrm{SiO}_{2}\right)$ chemical state $103.3 \mathrm{eV}$. The increase in $\mathrm{CL}$ indicates that the $\mathrm{SiO}_{2}$ is luminescent and thus contributing to the emission peak between 600 and $700 \mathrm{~nm} . \mathrm{SiO}_{2}$ is a wide band gap phosphor material and the electron beam irradiation can break the $\mathrm{Si}-\mathrm{O}$ bonds and cause intrinsic defects [45]. Skuja et al. [46] reported two peak intensities for $\mathrm{SiO}_{2}$ at $1.9 \mathrm{eV}(650 \mathrm{~nm})$ and $2.7 \mathrm{eV}(459 \mathrm{~nm})$ with a theory that the two peaks are related to intrinsic defects involving cleavage of the $\mathrm{Si}-\mathrm{O}$ bonds. A definite contribution from the $\mathrm{SiO}_{2} 1.9 \mathrm{eV}$ defect to the transition from the higher $5 \mathrm{~d}$ levels to the $4 \mathrm{f}_{7 / 2}$ levels leads to the increase in the CL intensity and peak emission between 600 and $700 \mathrm{~nm}$, thus also resulting in the change in color. The formation of the luminescent $\mathrm{SiO}_{2}$ layer on the surface of the $\mathrm{Y}_{2} \mathrm{SiO}_{5}$ :Ce therefore leads to the degradation of the blue emitting $\mathrm{Y}_{2} \mathrm{SiO}_{5}$ :Ce phosphor powders.
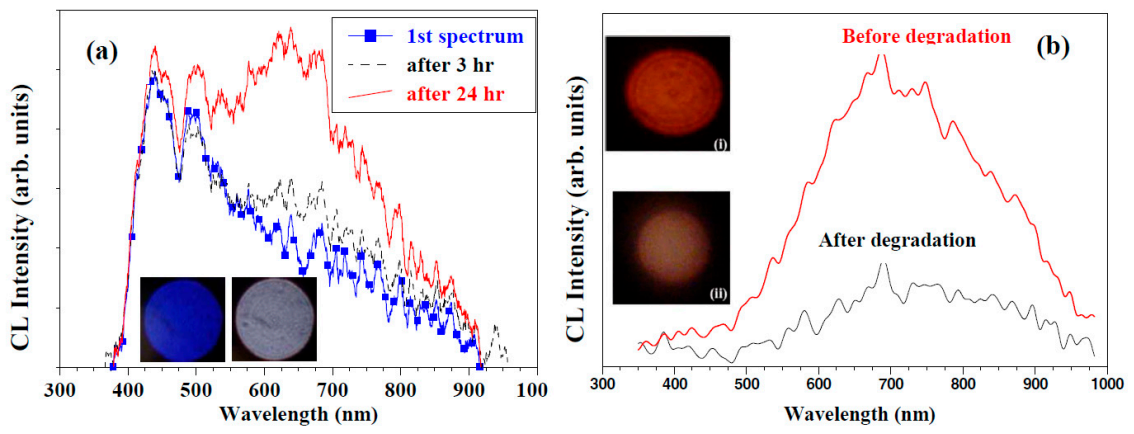

Figure 7. CL intensity against the wavelength for the light emitted from the powders: (a) before and after $3 \mathrm{~h}$ and $24 \mathrm{~h}$ electron bombardment of $\mathrm{Y}_{2} \mathrm{SiO}_{5}: \mathrm{Ce}$ [42]; and (b) $\mathrm{SiO}_{2}: \mathrm{PbS}$ nanoparticles before and after degradation [47] with a $2 \mathrm{keV}$ electron beam at a $1 \times 10^{-7}$ Torr $\mathrm{O}_{2}$ pressure. The digital images were taken before and after degradation. 

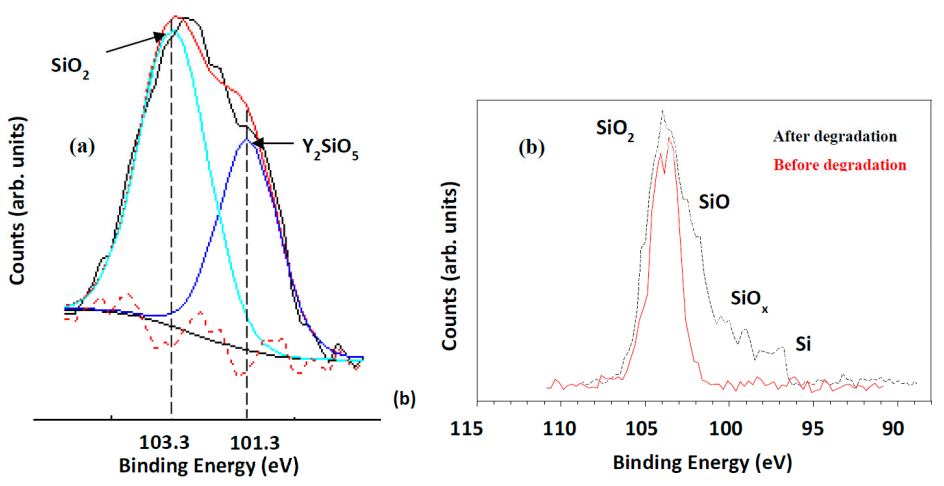

Figure 8. (a) XPS fitted results for the $\mathrm{Si} 2 \mathrm{p}$ in the $\mathrm{Y}_{2} \mathrm{SiO}_{5}: \mathrm{Ce}$ after degradation [42] $24 \mathrm{~h}$ degradation in an oxygen pressure of $1 \times 10^{-6}$ Torr with the electron current density at $26.3 \mathrm{~mA} \cdot \mathrm{cm}^{-2}$; and (b) the XPS of $\mathrm{SiO}_{2}: \mathrm{PbS}$ nanoparticles before and after degradation [47] with a $2 \mathrm{keV}$ electron beam at a $1 \times 10^{-7}$ Torr $\mathrm{O}_{2}$ pressure.

\subsection{4. $\mathrm{SiO}_{2}-\mathrm{PbS}$}

Figure $7 \mathrm{~b}$ presents the broad CL spectra of $\mathrm{SiO}_{2} ; 0.134 \mathrm{~mol} \%-\mathrm{PbS}$ nanoparticles, synthesized with a sol-gel method, before and after degradation with the maximum intensity at the wavelength of about $680 \mathrm{~nm}$ [47]. XPS showed that during degradation in an oxygen atmosphere the $\mathrm{SiO}_{2}$ is reduced to $\mathrm{SiO}_{\mathrm{x}}$ by the desorption of oxygen from the surface during electron bombardment and the surface was left enriched in elemental Si, as shown in Figure 8b. Dhlamini et al. [47] found that the rate of degradation of the CL intensity decreased with an increase in the oxygen pressure. The decrease in CL intensity is best explained in terms of the formation of a less efficient $\mathrm{SiO}_{\mathrm{x}}(0<x<2)$ layer on the surface.

\subsection{5. $\mathrm{CaO}: \mathrm{Bi}$}

Degradation was also tested on synthesized CaO:Bi powder [48]. As indicated in Figure 9, the CL emission intensity after a $430 \mathrm{C} / \mathrm{cm}^{2}$ electron dose decreased to around $40 \%$ of the original emission intensity. The inset also represents the exponential decrease of the CL intensity as function of prolonged electron beam irradiation. The differences in color and in the homogeneous distribution of the color are clear in the digital images taken before and after degradation (Figure 9a,b, respectively). XPS [48] indicated that the degradation occurred due to ESSCRs. A Ca enriched non-luminescent surface layer formed due to the ESSCR and was responsible for the CL degradation.

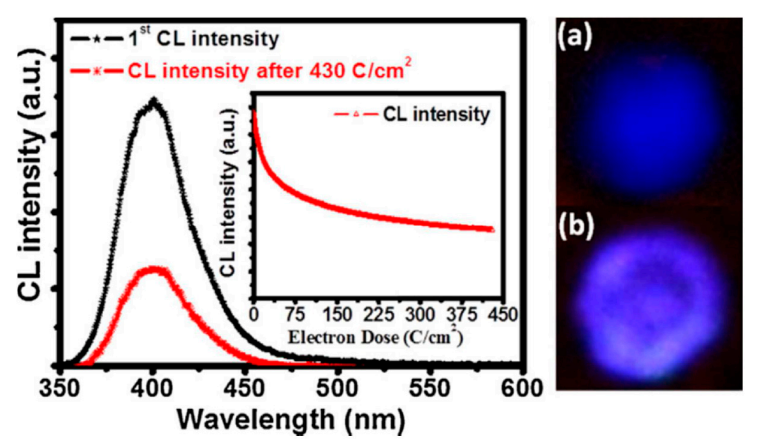

Figure 9. The $\mathrm{CL}$ emission spectra of the $\mathrm{CaO}: \mathrm{Bi}$ powder before and after $430 \mathrm{C} / \mathrm{cm}^{2}$. The inset represent the $\mathrm{CL}$ intensity as function of prolonged electron irradiation (up to $430 \mathrm{C} / \mathrm{cm}^{2}$ ), with a $2 \mathrm{keV}$ electron beam as working beam voltage and a $10 \mu \mathrm{A}$ beam current. (a,b) Digital images before and after degradation, respectively, are shown [48] (Note that, although the brightness of the digital image photo (b) appears brighter it was a camera art effect-it was clear with the naked eye that the intensity drop severely with degradation-a change in the image of $(\mathbf{a}, \mathbf{b})$, however, is clear). 
A $\mathrm{ZnO}$ thin film was successfully synthesized by the sol-gel method using the spin coater technique and annealed at $600{ }^{\circ} \mathrm{C}$ in air for two hours and in $\mathrm{Ar} / \mathrm{H}_{2}$ (5\%) flow for another $60 \mathrm{~min}$ [49]. $\mathrm{CL}$ degradation during prolonged electron irradiation on the annealed films was also determined. The CL study revealed that the intensity of the green emission $(511 \mathrm{~nm})$ was stable during electron bombardment for electron doses of more than $160 \mathrm{C} / \mathrm{cm}^{2}$, Figure 10a. Although the CL characteristics of the degraded sample remained the same as before degradation some surface morphology changes occurred beneath the beam during the degradation process, as can be seen in the Atomic Force Microscope (AFM) micrographs in Figure 10b [49]. It seems that a coalition of the particles occurred during prolonged electron bombardment.
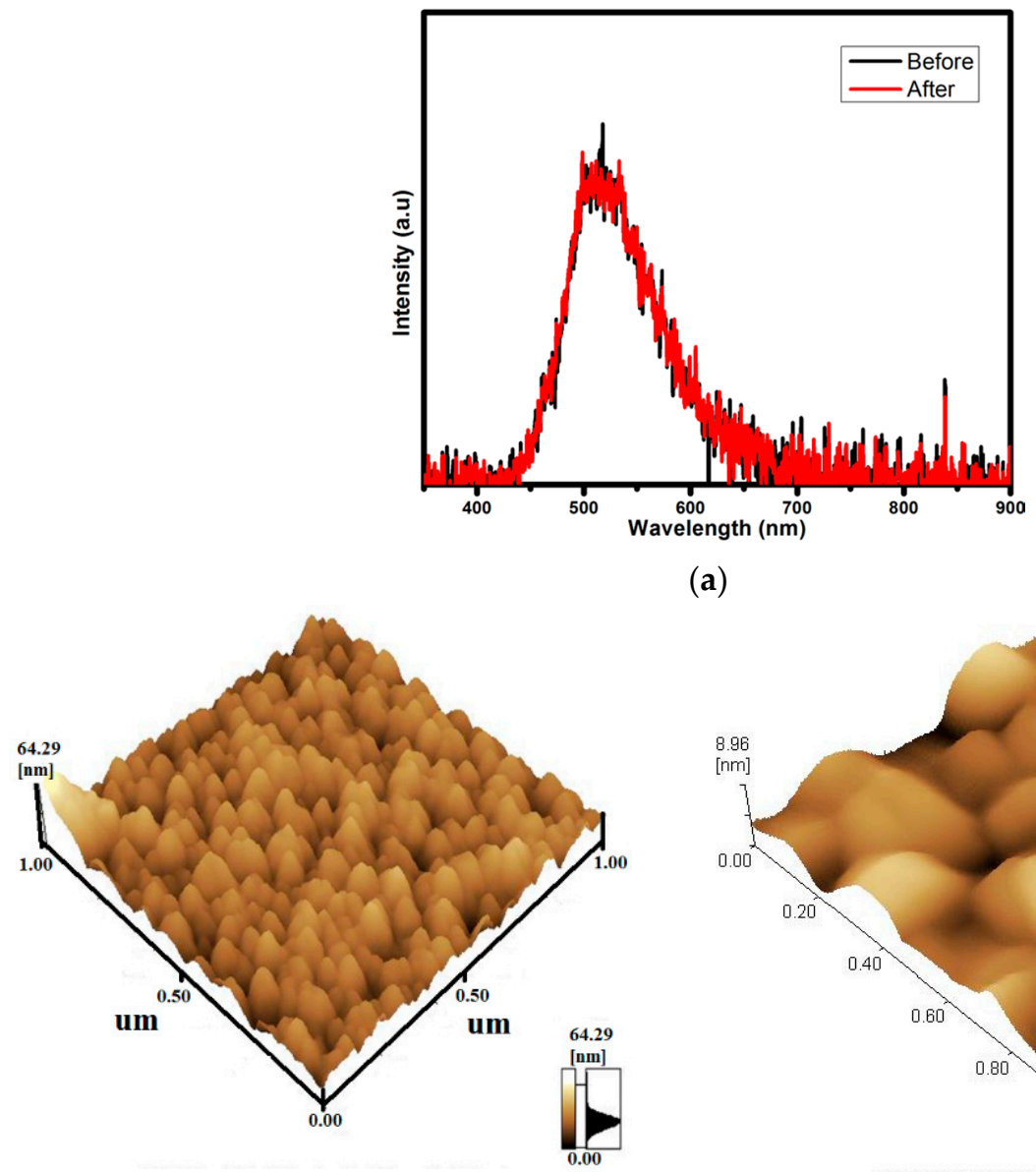

(a)

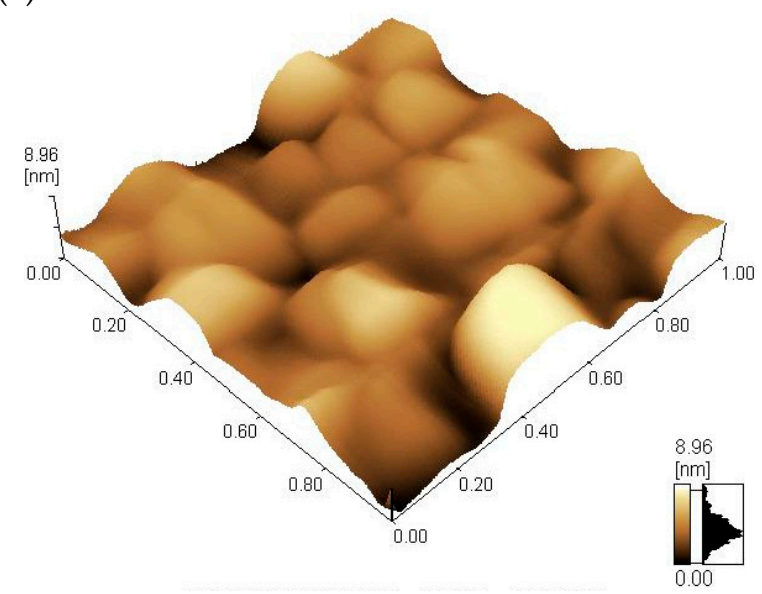

(b)

Figure 10. (a) The CL spectra before and after degradation of the $\mathrm{ZnO}$ film exposed to $\mathrm{H}_{2}$ flow for $60 \mathrm{~min}$; and (b) AFM micrographs of the sol-gel $\mathrm{ZnO}$ film, measured before degradation and after degradation in the degraded area [49].

\subsubsection{ESSCR Mechanism}

In all the degradation studies, it was clear that the electron beam has to be on and gas species must be present in the degradation atmosphere for the ESSCR to occur. The degradation rate also depends on the type of gas, the current density, the temperature and the beam voltage [50]. Swart et al. [51] concluded that the surface reaction rate depends on the dissociation cross-section of the oxygen molecule and the time that an arriving oxygen molecule spends on the surface. The mean surface stay time is a function of surface temperature and decreases at higher temperatures. For the substrate atom 
undergoing a reaction followed by desorption, the rate of change of the surface concentration, $\mathrm{C}_{\mathrm{s}}$, can be expressed as [51]:

$$
\frac{d C_{s}}{d t}=-k C_{s} N \varnothing_{m a} J \tau_{a s} \sigma\left(\frac{\rho}{(2 \pi m k T)^{1 / 2}}\right)\left(\tau_{0} \exp \left(\frac{\Delta H_{d e s}}{k T}\right)\right)
$$

where $k$ is a chemical rate constant that depends on the activation energy of the chemical reaction, Cas is the concentration of the adsorbed atomic species that will react with the matrix, $N$ is the number of reactive atomic species produced from the parent molecule and depends upon the composition of the gases, $\Phi_{m a}$ is the dissociation cross-section of the molecules to atoms (which is a function of electron energy and current density), $J$ is the electron flux density (electrons $\mathrm{cm}^{-2} \mathrm{~s}^{-1}$ ), and $\tau_{a s}$ is the lifetime of a reactive atomic species. It is assumed that the rate of production of adsorbed atomic species limits the ESSCR rate. $\sigma$ is the sticking coefficient, $\rho$ is the pressure, $m$ is the molecular mass, $T$ is the temperature, $k$ is Boltzmann's constant, $\tau_{0}$ is a combination of the molecular partition functions of the system in the equilibrium and activated states and the vibration frequency of the crystal lattice, and $H_{\mathrm{des}}$ is the desorption energy.

\subsection{Defect Emission-XPS and HRTEM}

From the above, it is clear that the AES and XPS techniques are excellent methods to monitor the CL degradation process. XPS, however, may also be used as an indication of the presence of defects in some phosphor materials, as well as to find the oxidation state of the rare earth dopant, with the possible chemical composition thereof. Figure 11 a shows the O-1s peak of a ZnO phosphor powder containing a large amount of oxygen related defects [4] and Figure 11b shows the O-1s peak of ZnO powder doped with a high concentration of $\mathrm{Tb}$ [52]. The defect containing $\mathrm{ZnO}$ was prepared by using zinc nitrate as precursors with the combustion method and the $\mathrm{Tb}(6 \mathrm{~mol} \%)$ with the solution combustion method. Figure 11a indicates that the O-1s peak may be fitted with three peaks, namely $\mathrm{O} 1$ ( $\mathrm{ZnO}), \mathrm{O} 2$ (deficient oxygen; OH groups) and O3 (adsorbed species) centered at 530.3, 531.2 and $532.6 \mathrm{eV}$, respectively as indicated. A broad orange-red emission from 500 to $850 \mathrm{~nm}$ (not shown) was obtained from the $\mathrm{ZnO}$ prepared with the nitrate precursor which may be attributed to different kinds of defects $\left(\mathrm{O}_{i}, \mathrm{O}_{v}, \mathrm{Zn}_{i}\right.$ and $\mathrm{Zn}_{v}$ with $i$ and $v$ interstitials and vacancies). The $\mathrm{O}-1 \mathrm{~s}$ peak of the $6 \mathrm{~mol} \%$ doping of $\mathrm{Tb}$ contains four peaks. The peaks are as indicated above (O1-O3) plus an extra peak at $528.7 \mathrm{eV}$ which is due to the formation of $\mathrm{Tb}_{2} \mathrm{O}_{3}$ [53]. When $\mathrm{Tb}^{3+}$ ions are doped in the $\mathrm{ZnO}$ matrix, $\mathrm{Tb}^{3+}$ may occupy the sites of the $\mathrm{Zn}^{2+}$ ions, interstitial sites as well as the $\mathrm{V}_{\mathrm{Zn}}$ sites in the $\mathrm{ZnO}$ lattice and emits different light color due to the newly created native defects as well as from the $\mathrm{Tb}^{3+}$ f-f transitions [54]. Kumar et al. [55] investigated the role of surface and deep level defects on the blue emission of tin oxide quantum dots $\left(\mathrm{SnO}_{2} \mathrm{QDs}\right)$ synthesized at different temperatures by the solution-combustion method by using XPS, HRTEM and PL techniques. HRTEM revealed an increase in the average dot size from 2.2 to $3.6 \mathrm{~nm}$ (with Selected area electron diffraction (SAED) patterns, Figure 12) with an increasing combustion temperature from 350 to $550{ }^{\circ} \mathrm{C}$, Figure 12 . A decrease in the band gap value from 3.37 to $2.76 \mathrm{eV}$ was observed with the increase in dot size due to the quantum confinement effect [55]. The PL emission showed a broad blue emission band for all the combustion temperatures studied. The $350{ }^{\circ} \mathrm{C}$ PL emission is shown as an inset in Figure 12. The fitted curve shows two peaks at 400 and $430 \mathrm{~nm}$. This was due to the creation of various oxygen and Sn vacancies/defects as confirmed by X-ray photoelectron spectroscopy data (Figure 11c,d). Both Sn-3d and O-1s XPS peaks indicated the formation of defects in the $\mathrm{SnO}_{2}$ as indicated in Figure 11c,d) [55]. The O-1s also contains the $\mathrm{O}_{2}$ defect peak and the broadening of the $\mathrm{Sn}-3 \mathrm{~d}$ peaks at the low energy side also gives an indication of the presence of the defects in the material. 

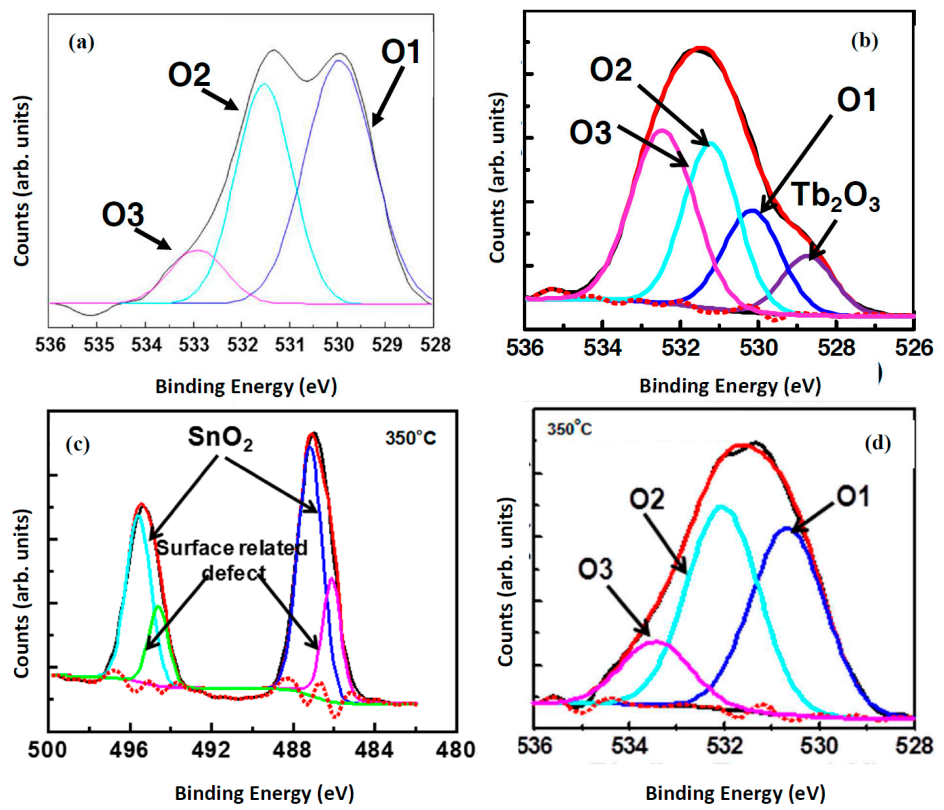

Figure 11. De-convolution of the O-1s peak of: (a) defect containing $\mathrm{ZnO}$ [4]; (b) $\mathrm{ZnO}$ with $6 \mathrm{~mol} \%$ doping of $\mathrm{Tb}[45]$; (c) $\mathrm{Sn}-3 \mathrm{~d}_{5 / 2}$ and $\mathrm{Sn}-3 \mathrm{~d}_{3 / 2}$ peaks of $\mathrm{SnO}_{2}$; and (d) O- $1 \mathrm{~s}$ of $\mathrm{SnO}_{2}$ [55].
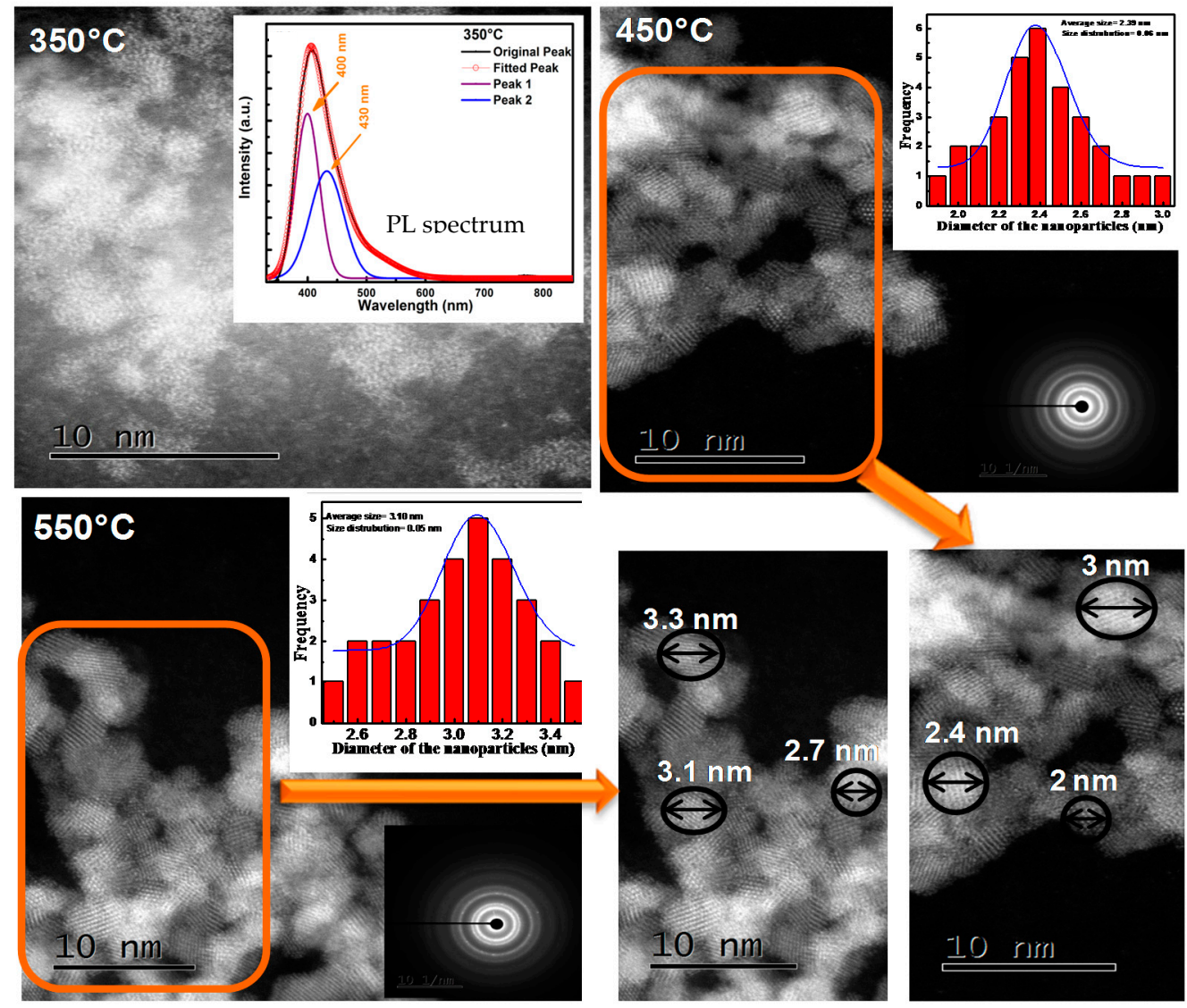

Figure 12. HRTEM images of $\mathrm{SnO}_{2}$ QDs with SAED patterns at different combustion temperatures with the $350{ }^{\circ} \mathrm{C}$ PL spectrum as an inset [55]. 


\subsection{Oxidation/Valence State-XPS}

A good example of using XPS for determining the oxidation/valence states is $\mathrm{CaO}: \mathrm{Bi}$. The $\mathrm{CaO}: \mathrm{Bi}$ powder was synthesized by the sol-gel combustion method. The powder was then annealed in air at $1200{ }^{\circ} \mathrm{C}$ for $2 \mathrm{~h}$. In order to assess the presence of the Bi in the surface layer for the sample, XPS measurements were carried out on the sample's surface (Figure 13a) [48]. The Bi 4f XPS spectra exhibit two peaks with two shoulders which suggest that the Bi was in doublet oxidation states. The two main peaks appear with their centers at $164.3 \mathrm{eV}$ and $158.9 \mathrm{eV}$, which were deconvoluted into two peaks. These peaks correspond to the $\mathrm{Bi}^{4} \mathrm{f}_{5 / 2}$ and $\mathrm{Bi}^{4} \mathrm{f}_{7 / 2}$ binding energies of $\mathrm{Bi}^{3+}$ in $\mathrm{Bi}_{2} \mathrm{O}_{3}$ [56]. The shoulders centered at $162.7 \mathrm{eV}$ and $157.1 \mathrm{eV}$ were similarly deconvoluted into two peaks. These peaks were ascribed to the $\mathrm{Bi}^{4} \mathrm{f}_{5 / 2}$ and $\mathrm{Bi}^{4} \mathrm{f}_{7 / 2}$ binding energies of $\mathrm{Bi}^{2+}$ in $\mathrm{BiO}$ [56]. This is evidence of the presence of the $\mathrm{Bi}$ with two different valence states, namely, $\mathrm{Bi}^{3+}$ and $\mathrm{Bi}^{2+}$. Figure $13 \mathrm{~b}$ shows the CL spectra measured at different beam voltages that ranged from 1 to $3 \mathrm{keV}$. The emission changed mainly in the blue region to the orange red region with an increase in beam voltage. The blue and orange emissions were reported by many authors as a characteristic emission from $\mathrm{Bi}^{3+}$ and $\mathrm{Bi}^{2+}$ respectively $[57,58]$. A simplified energy level diagram, with the respected obtained color images, from Reference [48], is given in Figure 14. These diagrams explain the difference in emission between the $\mathrm{Bi}^{3+}$ and $\mathrm{Bi}^{2+}$ responsible for the different light colors obtained.
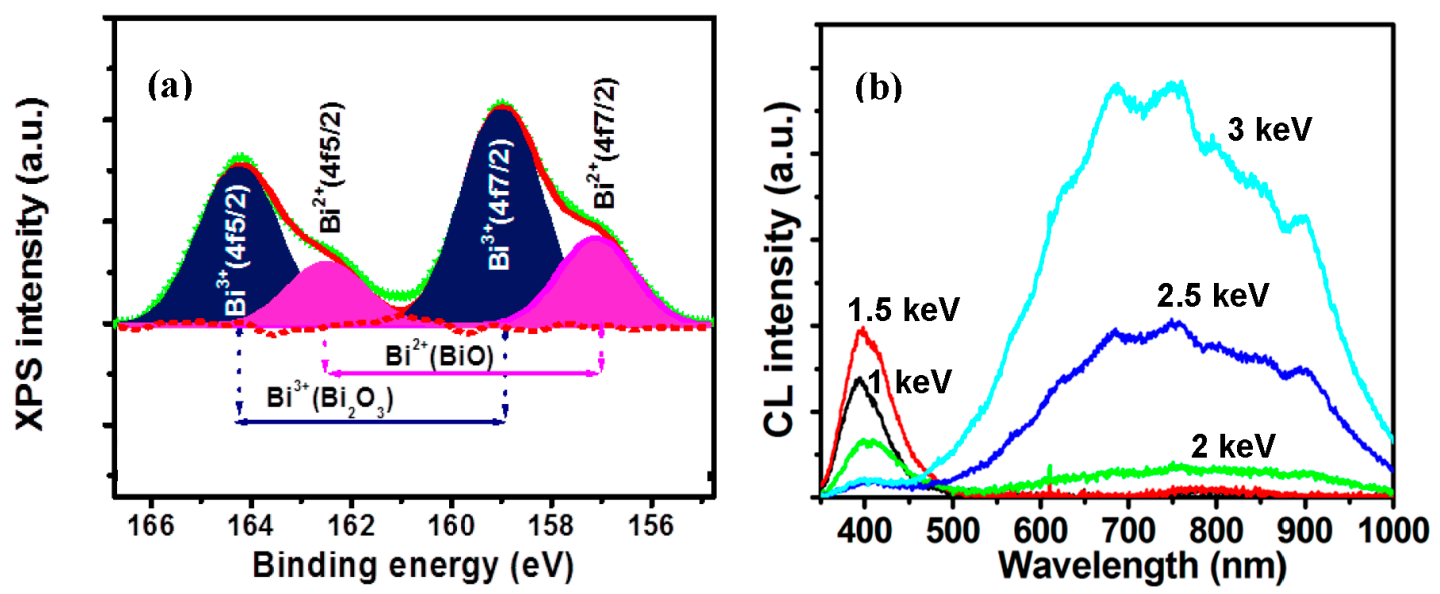

Figure 13. (a) Bi $4 \mathrm{f}$ high resolution deconvoluted XPS spectrum of a $1200{ }^{\circ} \mathrm{C}$ post-annealed CaO:Bi phosphor powder; and (b) CL spectra obtained at different beam voltages (1-3 keV) [48].
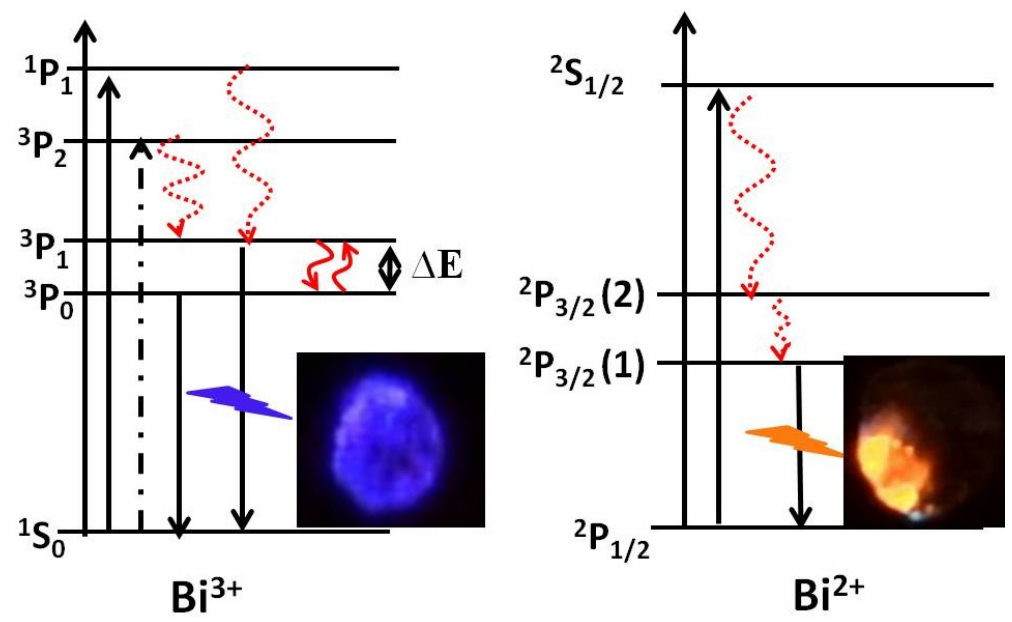

Figure 14. The simplified energy level diagrams of $\mathrm{Bi}^{3+}$ and $\mathrm{Bi}^{2+}$ species and the photographs of their respective luminescence [48]. 


\subsection{Oxidation/Valence State-TOF-SIMS}

Normally, it is very difficult to distinguish between two oxidation states with time-of-flight secondary ion mass spectrometry (TOF-SIMS, Ion-tof GmbH, Münster, Germany), but it was shown that the technique allows full molecular and isotopic characterization of the matrix chemistry. The two states were detected in $\mathrm{Sr}_{5}\left(\mathrm{PO}_{4}\right)_{3} \mathrm{~F}: \mathrm{Eu}$ (Figure 15) [59], by monitoring the $\mathrm{EuF}^{+}$and $\mathrm{EuF}_{2}{ }^{+}$species, ostensibly the $\mathrm{Eu}^{2+}$ and $\mathrm{Eu}^{3+}$ oxidation states, respectively. Ahmed et al. [60] found that at dopant concentration levels in a host material, the prospect of differentiating $\mathrm{Ce}^{3+}$ and $\mathrm{Ce}^{4+}$ ions using TOF-SIMS was poor. They found that for $\mathrm{SiO}_{2}$ : $\mathrm{Ce}(4 \mathrm{~mol} \%)$ samples which had been annealed in air or reduced in $\mathrm{H}_{2} / \mathrm{Ar}$, that no significant differences could be detected by using TOF-SIMS, despite a difference in the $\mathrm{Ce}^{3+} / \mathrm{Ce}^{4+}$ ratio assessed by XPS and PL. For the best-case scenario of a Ce compound, some differences in the TOF-SIMS signals from $\mathrm{CeF}_{4}$ and $\mathrm{CeF}_{3}$ were found. Significantly, a tiny $\mathrm{CeF}^{3+}$ ion signal present from the $\mathrm{CeF}_{4}$ sample and associated with $\mathrm{Ce}^{4+}$ was absent from the $\mathrm{CeF}_{3}$ sample. This and/or differences in the relative peak sizes might be used to locate $\mathrm{Ce}^{4+}$ ions in fluoride materials, but using TOF-SIMS to determine the oxidation state of $\mathrm{Ce}$ is still challenging and more research studies are needed.

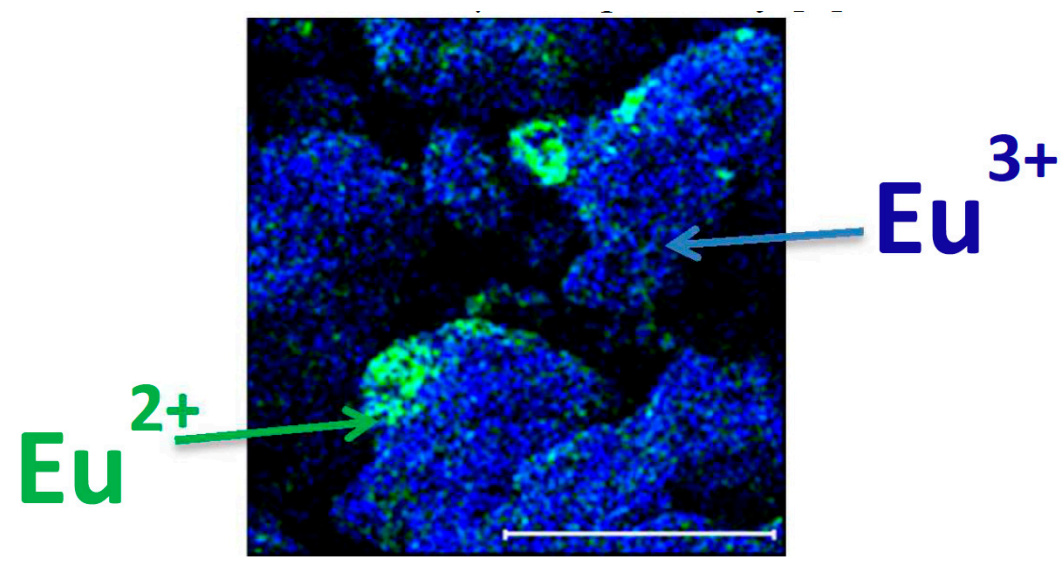

Figure 15. TOF-SIMS chemical imaging indicating the differences in oxidation state and distribution of the $\mathrm{Eu}^{3+}$ dopant and the $\mathrm{Eu}^{2+}$ contaminant using a false color overlay of the $\mathrm{Eu}(\mathrm{II}) \mathrm{F}^{+}(172 \mathrm{~m} / \mathrm{z}$; green) ion and the $\mathrm{Eu}(\mathrm{III}) \mathrm{F}^{2+}(191 \mathrm{~m} / \mathrm{z}$; blue) ion [59].

\subsection{Surface Enhanced Raman Scattering}

Noble nanoparticles (NPs) combined with other optical related material such as $\mathrm{TiO}_{2}$ exhibit various desirable properties such as optical and antibacterial properties that make them suitable for the future nano-biotechnology and photocatalytic applications. One example is the plasmonic $\mathrm{Ag}-\mathrm{TiO}_{2}$ nano-biocomposite synthesized by the sol-gel technique and their optical, surface enhanced Raman scattering (SERS). For these kinds of optical research, the HRTEM and Raman measurements are vital to explain the properties. Prakash et al. [61] found a decrease in the PL intensity with an increasing Ag NP concentration that was attributed to the decreased recombination of photo-induced electrons and holes which were trapped by the synergy in the Ag $3 \mathrm{~d}$ energy level below the conduction band in the $\mathrm{TiO}_{2} \mathrm{NPs}$. In general, these properties such as charge separation and decreased recombination of photo-induced electrons and holes of the $\mathrm{Ag}-\mathrm{TiO}_{2}$ nanocomposites are useful for improving the photocatalytic properties of the materials. The narrow emission PL bands of the $\mathrm{Ag}-\mathrm{TiO}_{2}$ nanocomposites as can be seen in PL emission spectra (not shown), may additionally be useful for their application as selective optical windows [62]. Prakash et al. monitored the SERS activity of methyl orange (MO) molecules on the surface of the $\mathrm{TiO}_{2}$ and $\mathrm{Ag}-\mathrm{TiO}_{2}$ nanocomposite particles. The inset of Figure 16 shows the SERS signals of the aqueous $\mathrm{MO}$ solution with $\mathrm{TiO}_{2}$ and $\mathrm{Ag}-\mathrm{TiO}_{2}$ nanocomposite particles with an increasing Ag concentration, Figure 16 ((d)—a to d) [61]. The SERS signals become 
stronger at higher Ag concentrations. A full description about the stronger signal can be found in Reference [46]. The important part of the $\mathrm{Ag}-\mathrm{TiO}_{2}$ as an example is the use of HRTEM in combination of EDS to indicate and found the positions of these NPs on the $\mathrm{TiO}_{2}$ particles (Figure 16a-c) [61]. The lighter spots on the HRTEM image are due to the Ag NPs as pointed out with EDS maps of the particle. The Ag NPSs are mostly positioned on the surface of the $\mathrm{TiO}_{2}$.

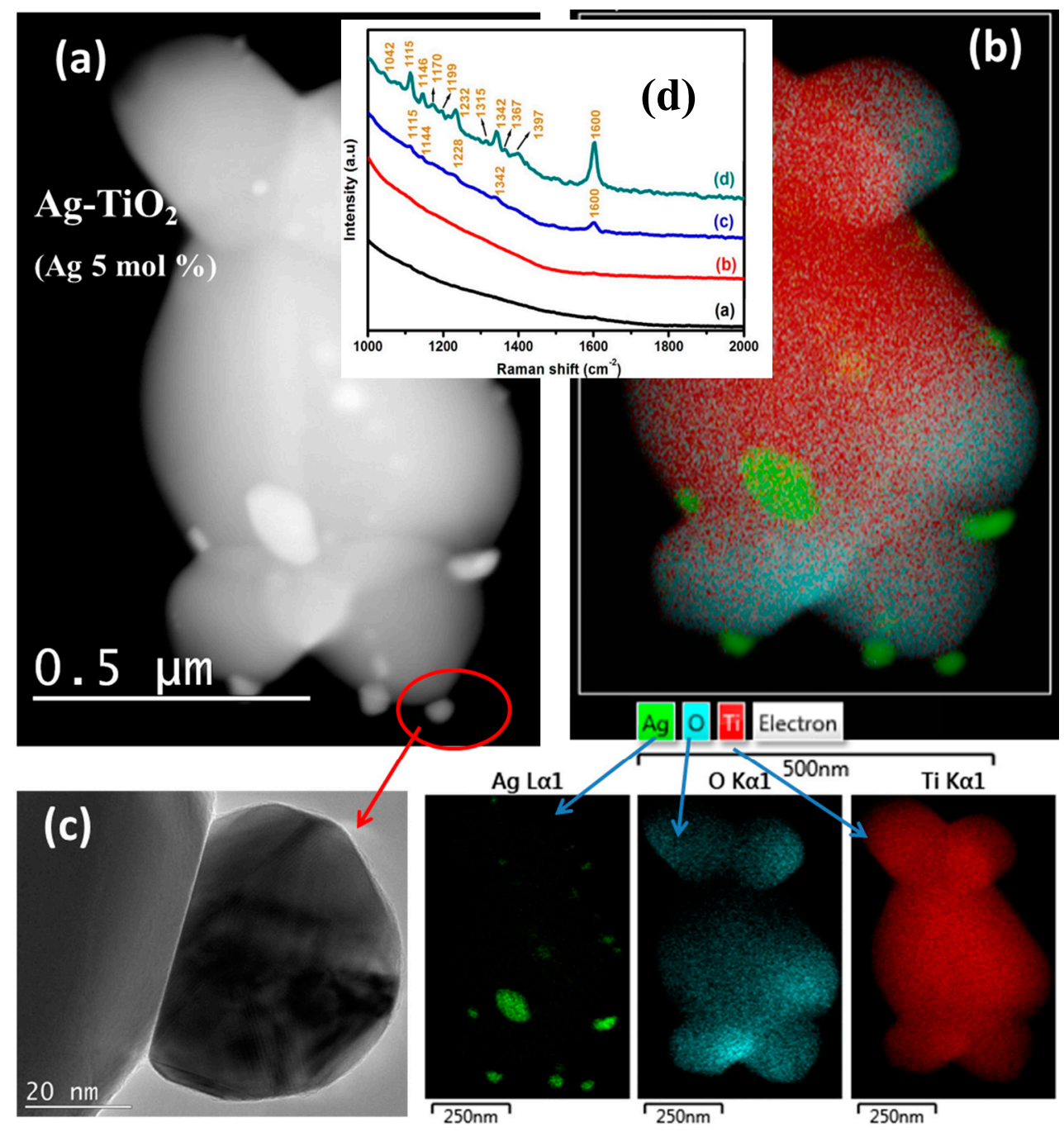

Figure 16. (a) Layered image, high-angle annular dark-field (HAADF) STEM micrograph; and (b) corresponding EDS mapping of $\mathrm{Ag}-\mathrm{TiO}_{2}$ nanocomposites with a $5 \mathrm{~mol} \%$ concentration (including EDS maps with HAADF micrograph). Individual EDS Maps for the elements Ag, $\mathrm{O}$ and Ti are shown. (c) HRTEM image of an Ag NP that sits on the surface of the $\mathrm{TiO}_{2}$ particle. Inset (d) shows the SERS signals of the aqueous $\mathrm{MO}$ solution on the surface of the: (a) $\mathrm{TiO}_{2}$; and $\mathrm{Ag}-\mathrm{TiO}_{2}$ nanocomposite particles with Ag: (b) $1 \mathrm{~mol} \%$; (c) $3 \mathrm{~mol} \%$; and (d) $5 \mathrm{~mol} \%$ [61].

\subsection{General}

The examples of the results presented in this review show that the combination of AES, XPS, TOF-SIMS and HRTEM analysis can be used to obtain useful and complementary information regarding the surface and interface characteristics of phosphor materials that are complimentary to optical properties techniques. AES in combination with CL provides excellent info about the electron stimulated reactions due to electron beam radiation, while XPS and TOF-SIMS can help to determine the valence/oxidation state of the dopant and the host. XPS also may help in determining the presence 
of defects in the phosphor materials. Using an AES system with a focused and rastered electron beam, it is possible to obtain a secondary electron image as well as an elemental map of the same area of the sample surface in order to determine if dopants are completely dissolved into the host matrix. HRTEM in combination with EDS can indicated the positions of the doped nanoparticles into the host material. The main advantage of using the XPS-technique lies in the fact that the binding energy of a photoelectron is sensitive to the chemical surrounding of the atom' there is a chemical shift in the binding energy. These shifts are very important since they provide a tool to identify individual chemical states of an element. Unfortunately, it is not always straightforward to interpret these chemical shifts because they depend both on initial and final state effects and then other techniques like TOF-SIMS and AES come in much more handy. It should, however, further be pointed out that ToF-SIMS is in principle is a very simple analysis technique and its high mass resolution helps to give good possibilities to identify the surface constituents of an unknown sample nut it is not always straightforward to interpret the mass spectrum due to the large amount of information obtained when a spectrum is acquired. The possibility of getting useful information from the ToF-SIMS technique increases if a known sample is measured and if used in combination with other techniques. It is then possible to draw conclusions about the structure and orientation of molecules on a surface.

\section{Conclusions}

The examples of AES, XPS, TOF-SIMS and HRTEM analysis illustrate the importance of these techniques in the development of new phosphor materials. The detection of chemical species and defects that formed on the surface and in bulk phosphor materials can help with the design of other luminescent materials. The explanation of the luminescent mechanism is much easier if the valence state of the dopant is known.

Acknowledgments: This work is based on the research supported by the South African Research Chairs Initiative of the Department of Science and Technology and National Research Foundation of South Africa (84415). The financial support from the University of the Free State is highly recognized. Special thanks to all post docs and post graduate students that have contributed towards all the referenced work over the years.

Author Contributions: HC Swart as sole author wrote the paper from research work done in his group over the past 22 years.

Conflicts of Interest: The authors declare no conflict of interest.

\section{References}

1. Swart, H.C.; Terblans, J.J.; Ntwaeaborwa, O.M.; Coetsee, E.; Mothudi, B.M.; Dhlamini, M.S. Photon emission mechanisms of different phosphors. Nucl. Instrum. Methods B 2009, 267, 2630-2633. [CrossRef]

2. Shionoya, S.; Yen, W.M.; Yamamoto, H. Phosphor Handbook; CRC Press: Boca Raton, FL, USA, 1999.

3. Tannas, L.E., Jr. Flat-Panel Displays and CRT's; VanNostrand-Reinhold: New York, NY, USA, 1985.

4. Kumar, V.; Swart, H.C.; Ntwaeaborwa, O.M.; Kroon, R.E.; Terblans, J.J.; Shaat, S.K.K.; Yousif, A.; Duvenhage, M.M. Origin of the red emission in zinc oxide nanophosphors. Mater. Lett. 2013, 110, 57-60. [CrossRef]

5. Nagpure, I.M.; Pitale, S.S.; Coetzee, E.; Ntwaeaborwa, O.M.; Terblans, J.J.; Swart, H.C. Lattice site dependent cathodoluminescence behaviour and surface chemical changes in $\mathrm{Sr}_{5}\left(\mathrm{PO}_{4}\right)_{3} \mathrm{~F}$ host. Phys. B Phys. Condens. Matter 2012, 407, 1505-1508. [CrossRef]

6. Mothudi, B.M.; Ntwaeaborwa, O.M.; Botha, J.R.; Swart, H.C. Photoluminescence and phosphorescence properties of $\mathrm{MAl}_{2} \mathrm{O}_{4}: \mathrm{Eu}^{2+}, \mathrm{Dy}^{3+}(\mathrm{M}=\mathrm{Ca}, \mathrm{Ba}, \mathrm{Sr})$ phosphors prepared at an initiating combustion temperature of $500{ }^{\circ} \mathrm{C}$. Phys. B Phys. Condens. Matter 2009, 404, 4440-4444. [CrossRef]

7. Nagpure, I.M.; Pitale, S.S.; Coetsee, E.; Ntwaeaborwa, O.M.; Terblans, J.J.; Swart, H.C. Cathodoluminescence properties and surface characterization of $\mathrm{Sr}_{3}\left(\mathrm{PO}_{4}\right)_{2}: \mathrm{Tb}$ phosphor. Appl. Surf. Sci. 2011, 257, 10147-10155. [CrossRef] 
8. Swart, H.C.; Terblans, J.J.; Ntwaeaborwa, O.M.; Kroon, R.E.; Coetsee, E.; Nagpure, I.M.; Kumar, V.; Kumar, V.; Kumar, V. Applications of AES, XPS and TOF SIMS to phosphor materials. Surf. Interface Anal. 2014, 46, 1105-1109. [CrossRef]

9. Reisfeld, R.; Pantra, A.; Panczer, G.; Gaft, M. Spectroscopic properties of cerium in sol-gel glasses. Opt. Mater. 1999, 13, 81-88. [CrossRef]

10. Meltzer, R.S.; Feofilov, A.P. Spectral hole burning in the $4 \mathrm{f}-5 \mathrm{~d}$ transition of $\mathrm{Ce}^{3+}$ in $\mathrm{LuPO}_{4}$ and $\mathrm{YPO}_{4}$. J. Lumin . 2003, 102-103, 151-155. [CrossRef]

11. Ganjali, M.R.; Zare-Dorabei, R.; Norouzi, P. Design and construction of a novel optical sensor for determination of trace amounts of dysprosium ion. Sens. Actuators B Chem. 2009, 143, 233-238. [CrossRef]

12. Akinlua, A.; Torto, N.; Ajayi, T.R. Determination of rare earth elements in Niger Delta crude oils by inductively coupled plasma-mass spectrometry. Fuel 2008, 87, 1469-1477. [CrossRef]

13. Zhang, N.; Huang, C.; Hu, B. ICP-AES determination of trace rare earth elements in environmental and food samples by on-line separation and preconcentration with acetylacetone-modified silica gel using microcolumn. Anal. Sci. 2007, 23, 997-1002. [CrossRef] [PubMed]

14. Marsh, S.F. Separation of lanthanide fission products from nuclear fuels by extraction chromatography and cation exchange for isotope dilution mass spectrometric analysis. Anal. Chem. 1967, 39, 641-645. [CrossRef]

15. Sun, S.; Wu, X.; Yang, J.; Li, L.; Wang, Y. Determination of dysprosium by resonance light scattering technique in the presence of BPMPHD. Spectrochim. Acta Part A 2004, 60, 261-264. [CrossRef]

16. Li, J.; Liu, S.; Mao, X.; Gao, P.; Yan, Z. Trace determination of rare earths by adsorption voltammetry at a carbon paste electrode. J. Electroanal. Chem. 2004, 561, 137-142. [CrossRef]

17. Sun, Y. Detailed study on simultaneous separation of rare earth elements by capillary electrophoresis. J. Chromatogr. A 2004, 1048, 245-251. [CrossRef]

18. Orescanin, V.; Mikelic, L.; Roje, V.; Lulic, S. Determination of lanthanides by source excited energy dispersive $\mathrm{X}$-ray fluorescence (EDXRF) method after preconcentration with ammonium pyrrolidine dithiocarbamate (APDC). Anal. Chim. Acta 2006, 570, 277-282. [CrossRef] [PubMed]

19. Peter, B.S.; Panigrahi, K.S.; Viswanathan, C.K. Fluorescence enhancement of dysprosium, europium and terbium using sodium benzoate-trioctylphosphine oxide-Triton X-100. Anal. Chim. Acta 1992, 260, 135-141. [CrossRef]

20. Sano, K.; Terada, H.; Hidaka, Y.; Nishio, H.; Amakawa, Y. Ion-Microprobe Analysis of Rare Earth Elements in Oceanic Basalt Glass. Anal. Sci. 1999, 15, 743-748. [CrossRef]

21. Prasad, K.; Kala, R.; Rao, T.P.; Naidu, G.R.K. Ion imprinted polymer based ion-selective electrode for the trace determination of dysprosium(III) ions. Anal. Chim. Acta 2006, 566, 69-74. [CrossRef]

22. Holloway, P.H.; Ntwaeaborwa, O.M.; Swart, H.C. Electron-Stimulated Surface Chemical Reactions on Phosphors. J. Vac. Sci. Technol. A 2013, 31,1-12. [CrossRef]

23. Abrams, B.L.; Holloway, P.H. Role of the surface in luminescent processes. Chem. Rev. 2004, 104, 5783-5801. [CrossRef] [PubMed]

24. Knotek, M.L.; Feibelman, P.J. Stability of ionically bonded surfaces in ionizing environments. Surf. Sci. 1979, 90, 78-90. [CrossRef]

25. Redhead, P.A.; Hobson, J.P.; Kornelsen, E.V. The Physical Basis of Ultrahigh Vacuum; Plenum Press: New York, NY, USA, 1952.

26. Duvenhage, M.M.; Ntwaeaborwa, O.M.; Swart, H.C.; Visser, H.G. Synthesis, crystal structure, luminescent properties and photo degradation of mer-tris(8-Hydroxy-quinolinato-N,O)-indium(III) hydrate 0.5 methanol solvate. Opt. Mater. 2013, 35, 2366-2371. [CrossRef]

27. Koao, L.F.; Dejene, F.B.; Swart, H.C.; Botha, J.R. The effect of $\mathrm{Ce}^{3+}$ on structure, morphology and optical properties of flower-like ZnO synthesized using the chemical bath method. J. Lumin. 2013, 143, 463-468. [CrossRef]

28. Dutta, S.; Som, S.; Kunti, A.K.; Kumar, V.; Sharma, S.K.; Swart, H.C.; Visser, H.G. Structural and luminescence responses of $\mathrm{CaMoO}_{4}$ nano phosphors synthesized by hydrothermal route to swift heavy ion irradiation: Elemental and spectral stability. Acta Mater. 2017, 124, 109-119. [CrossRef]

29. Yousif, A.; Swart, H.C. Colour tuneable emission from $\left(\mathrm{Y}_{1.995-x} \mathrm{Ga}_{x}\right)_{2} \mathrm{O}_{3}: \mathrm{Bi}^{3+}$ phosphor prepared by a sol-gel combustion method. Mater. Lett. 2017, 186, 345-348. [CrossRef] 
30. Pitale, S.S.; Nagpure, I.M.; Kumar, V.; Ntwaeaborwa, O.M.; Terblans, J.J.; Swart, H.C. Investigations on the low voltage cathodoluminescence stability and surface chemical behaviour using Auger and X-ray photoelectron spectroscopy on $\mathrm{LiSrBO}_{3}: \mathrm{Sm}^{3+}$ phosphor. Mater. Res. Bull. 2011, 46, 987-994. [CrossRef]

31. Noto, L.L.; Pitale, S.S.; Gusowki, M.A.; Terblans, J.J.; Ntwaeaborwa, O.M.; Swart, H.C. Afterglow enhancement with $\mathrm{In}^{3+}$ codoping in $\mathrm{CaTiO}_{3}: \mathrm{Pr}^{3+}$ red phosphor. Powder Technol. 2013, 237, 141-146. [CrossRef]

32. Moulder, F.; Stickle, W.F.; Sobol, P.E.; Bomben, K.D. Handbook of X-ray Photoelectron Spectroscopy; ULVAC-PHI, Inc.: Chigasaki, Japan, 1995.

33. Oosthuizen, L.; Swart, H.C.; Viljoen, P.E.; Holloway, P.H.; Berning, G.L.P. Phosphor degradation under electron excitation. Appl. Surf. Sci. 1997, 120, 9-14. [CrossRef]

34. Itoh, S.; Kimizuka, T.; Tonegawa, T. Degradation Mechanism for Low Voltage Cathodoluminescence of Sulfide Phosphors. J. Electrochem. Soc. 1989, 136, 1819. [CrossRef]

35. Chen, S.H.; Greeff, A.P.; Swart, H.C. Degradation of $\mathrm{ZnS}: \mathrm{Cu}, \mathrm{Al}$,Au phosphor powder in different gas mixtures. J. Lumin. 2004, 109, 93-102. [CrossRef]

36. Swart, H.C.; Sebastian, J.S.; Trottier, T.A.; Jones, S.L.; Holloway, P.H. Degradation of Zinc Sulfide Phosphors under electron bombardment. J. Vac. Sci. Technol. A 1996, 14, 1697-1703. [CrossRef]

37. Holloway, P.H.; Sebastian, J.S.; Trottier, T.A.; Swart, H.C.; Peterson, R.O. Production and control of vacuum in Field Emission Flat Panel Displays. Solid State Technol. 1995, 38, 47-54.

38. Pitale, S.S.; Kumar, V.; Nagpure, I.M.; Coetsee, E.; Ntwaeaborwa, O.M.; Swart, H.C. Cathodoluminescent properties and surface characterization of bluish-white nanocrystalline $\mathrm{LiAl}_{5} \mathrm{O}_{8}: \mathrm{Tb}$ phosphor. J. Appl. Phys. 2011, 109, 013105. [CrossRef]

39. Richardson, F.S. Terbium(III) and europium(III) ions as luminescent probes and stains for biomolecular systems. Chem. Rev. 1982, 82, 541. [CrossRef]

40. Nsimama, P.D.; Ntwaeaborwa, O.M.; Swart, H.C. Auger electron/X-ray photoelectron and Cathodoluminescent Spectroscopic Studies of Pulsed Laser Ablated $\mathrm{SrAl}_{2} \mathrm{O}_{4}: \mathrm{Eu}^{2+}, \mathrm{Dy}^{3+}$ Thin Films. Appl. Surf. Sci. 2010, 257, 512. [CrossRef]

41. Shah, K.V.; Goswami, M.; Manikandan, S.; Shrikhande, V.K.; Kothiyal, G.P. Surface degradation behaviour of sodium borophosphate glass in aqueous media: Some studies. Bull. Mater. Sci. 2009, 32, 329. [CrossRef]

42. Coetsee, E.; Terblans, J.J.; Swart, H.C. Degradation of $\mathrm{Y}_{2} \mathrm{SiO}_{5}$ :Ce phosphor powders. J. Lumin. 2007, 126, 37-42. [CrossRef]

43. Zhang, Q.Y.; Pita, K.; Buddhudu, S.; Kam, C.H. Luminescent properties of rare-earth ion doped yttrium silicate thin film phosphors for a full-colour display. J. Phys. D Appl. Phys. 2002, 35, 3085. [CrossRef]

44. Bosze, E.J.; Hirata, G.A.; McKittrick, J. An Investigation of the Chromaticity of Blue Emitting Yttrium Silicate. Proc. Mater. Res. Soc. 1999, 558, 15. [CrossRef]

45. Liu, X.; Phang, J.C.H.; Chan, D.S.H.; Chim, W.K. The properties of $2.7 \mathrm{eV}$ cathodoluminescence from $\mathrm{SiO}_{2}$ film on Si substrate. J. Phys. D Appl. Phys. 1999, 32, 1563. [CrossRef]

46. Skuja, L.N.; Entzian, W. Cathodoluminescence of Intrinsic Defects in Glassy $\mathrm{SiO}_{2}$, $\mathrm{Thermal} \mathrm{SiO}_{2}$ Films, and $\alpha$-Quartz. Phys. Status Solidi A 1986, 96, 191. [CrossRef]

47. Dhlamini, M.S.; Terblans, J.J.; Ntwaeaborwa, O.M.; Swart, H.C. Synthesis and degradation of the PbS nanoparticle phosphors embedded in $\mathrm{SiO}_{2},\left(\mathrm{SiO}_{2}: \mathrm{PbS}\right)$. Surf. Rev. Lett. 2007, 14, 697-701. [CrossRef]

48. Yousif, A.; Jafer, R.M.; Som, S.; Swart, H.C. Ultra-broadband luminescent from Bi doped CaO matrix. RSC Adv. 2015, 5, 54115-54122. [CrossRef]

49. Hasabeldaim, E.; Ntwaeaborwa, O.M.; Kroon, R.E.; Craciun, V.; Coetsee, E.; Swart, H.C. Surface characterization and cathodoluminescence degradation of $\mathrm{ZnO}$ thin films. Appl. Surf. Sci. 2016. [CrossRef]

50. Swart, H.C.; Oosthuizen, L.; Holloway, P.H.; Berning, G.L.P. The degradation behaviour of ZnS phosphor powders under different experimental conditions. Surf. Interface Anal. 1998, 26, 337-342. [CrossRef]

51. Swart, H.C.; Hillie, K.T.; Greeff, A.P. The effect of temperature on the degradation of ZnS FED phosphors. Surf. Interface Anal. 2001, 32, 110-113. [CrossRef]

52. Kumar, V.; Som, S.; Kumar, V.; Kumar, V.; Ntwaeaborwa, O.M.; Coetsee, E.; Swart, H.C. Tunable and white emission from $\mathrm{ZnO}: \mathrm{Tb}^{3+}$ nanophosphors for solid state lighting applications. Chem. Eng. J. 2014, 255, 541-552. [CrossRef]

53. Ahmad, M.; Pan, C.; Luo, Z.; Zhu, J.A. A Single ZnO Nanofiber-Based Highly Sensitive Amperometric Glucose Biosensor. J. Phys. Chem. C 2010, 114, 9308-9313. [CrossRef] 
54. Pereira, A.S.; Peres, M.; Soares, M.J.; Alves, E.; Neves, A.; Monteiro, T.; Trindade, T. Synthesis, surface modification and optical properties of $\mathrm{Tb}^{3+}$-doped $\mathrm{ZnO}$ nanocrystals. Nanotechnology 2006, 17, 834. [CrossRef]

55. Kumar, V.; Kumar, V.; Som, S.; Neethling, J.; Olivier, E.J.; Ntwaeaborwa, O.M.; Swart, H.C. Role of surface and deep-level defect on the emission of tin oxide quantum dots. Nanotechnology 2014, 25, 135701. [CrossRef] [PubMed]

56. Vila, M.; Guerra, C.; Lorenz, K.; Piqueras, J.; Alves, E.; Nappinic, S.; Magnanoc, E. Structural and luminescence properties of $\mathrm{Eu}$ and $\mathrm{Er}$ implanted $\mathrm{Bi}_{2} \mathrm{O}_{3}$ nanowires for optoelectronic applications. J. Mater. Chem. C 2013, 1, 7920. [CrossRef]

57. Cao, R.; Zhang, F.; Liao, C.; Qiu, J. Yellow-to-orange emission from $\mathrm{Bi}^{2+}$-doped $\mathrm{RF}_{2}(\mathrm{R}=\mathrm{Ca}$ and Sr) phosphors. Opt. Express 2013, 21, 15728. [CrossRef] [PubMed]

58. Zhang, C.M.; Yang, J.; Lin, C.K.; Li, C.X.; Lin, J. Reduction of $\mathrm{Eu}^{3+}$ to $\mathrm{Eu}^{2+}$ in $\mathrm{MAl}_{2} \mathrm{Si}_{2} \mathrm{O}_{8}(\mathrm{M}=\mathrm{Ca}, \mathrm{Sr}, \mathrm{Ba})$ in air condition. J. Solid State Chem. 2009, 182, 1673. [CrossRef]

59. Swart, H.C.; Nagpure, I.M.; Ntwaeaborwa, O.M.; Fisher, G.L.; Terblans, J.J. Identification of Eu Oxidation States in a Doped $\mathrm{Sr}_{5}\left(\mathrm{PO}_{4}\right)_{3} \mathrm{~F}$ Phosphor by TOF-SIMS Imaging. Opt. Express 2012, 20, 17119-17125. [CrossRef]

60. Ahmed, H.A.A.S.; Swart, H.C.; Kroon, R.E. Investigating the capability of ToF-SIMS to determine the oxidation state of Ce ions. Phys. B Condens. Matter 2017. [CrossRef]

61. Prakash, J.; Kumar, P.; Harris, R.A.; Swart, C.; Neethling, J.H.; van Vuuren, A.J.; Swart, H.C. Synthesis, Characterization and Multifunctional Properties of Plasmonic Ag-TiO2. Nanotechnology 2016, 27, 355707. [CrossRef] [PubMed]

62. Chen, S.F.; Li, J.P.; Qian, K.; Xu, W.P.; Lu, Y.; Huang, W.X.; Yu, S.H. Large scale photochemical synthesis

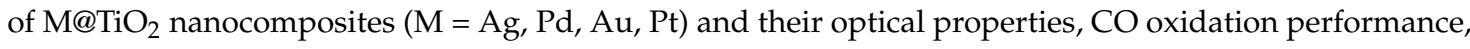
and antibacterial effect. Nano Res. 2010, 3, 244-255. [CrossRef]

(C) 2017 by the author. Licensee MDPI, Basel, Switzerland. This article is an open access article distributed under the terms and conditions of the Creative Commons Attribution (CC BY) license (http:/ / creativecommons.org/licenses/by/4.0/). 